\title{
Risk factors associated with mental illness in Oyo State, Nigeria: A Community based study
}

\author{
OE Amoran*1, TO Lawoyin ${ }^{1}$ and OO Oni ${ }^{2}$
}

\author{
Address: ${ }^{1}$ Department of Community Medicine, University College Hospital, Ibadan, Nigeria and ${ }^{2}$ Office of Medical officer of Health, Saki East \\ Local Govt Area, Oyo State, Nigeria \\ Email: OE Amoran* - drfamoran@yahoo.com; TO Lawoyin - tlawoyin@skannet.com; OO Oni - rindeoni@yahoo.com \\ * Corresponding author
}

Published: 22 December 2005

Annals of General Psychiatry 2005, 4:19 doi:10.1186/1744-859X-4-19

This article is available from: http://www.annals-general-psychiatry.com/content/4/1/19

(c) 2005 Amoran et al; licensee BioMed Central Ltd.

This is an Open Access article distributed under the terms of the Creative Commons Attribution License (http://creativecommons.org/licenses/by/2.0), which permits unrestricted use, distribution, and reproduction in any medium, provided the original work is properly cited.
Accepted: 22 December 2005
Received: 31 May 2005

\section{Introduction}

Mental health is defined as the capacity to work, capacity to love and the capacity to play and for recreation [1]. Approximately one in five of the world's youth, 15 years and younger suffer from mild to severe mental disorders. A large number of these children remain undetected and untreated [2]. It must be noted that mental health is one of the more recently added components of Primary Health Care (PHC) and means more than merely the pres-

\begin{abstract}
Background: The main objective of this study was to determine the prevalence and factors associated with mental illness in Oyo State at community level using the general health questionnaire as a screening tool.
\end{abstract}

Method: This cross-sectional, community- based survey was carried out among adults in three randomly selected LGAs using multi-stage sampling technique.

Results: A total of 1105 respondents were assessed in all. The overall prevalence of psychiatric morbidity in Oyo state Nigeria was found to be $21.9 \%$, (18.4\% in the urban areas and $28.4 \%$ in the rural areas, $p=0.005)$. Young age $\leq 19 \mathrm{yrs}\left(X^{2}=20.41, p=0.00013\right)$, Unemployment $\left(X^{2}=11.86\right.$ $p=0.0005)$, living condition below average $\left(X^{2}=12.21, p=0.00047\right)$, physical health $\left(X^{2}=6.07, p\right.$ $=0.014)$, and large family size $\left(X^{2}=14.09 p=0.00017\right)$ were associated with increase risk for .

logistic regression analysis, Unemployment (C.I conditions perceived to be above average $(C . I=1.99-5.50, O R-3.3)$ were significant predictors of mental illness while family size less than $6(C . I=0.86-0.97$, OR-0.9l $)$ was protective.

Conclusion: The teenagers and the rural populations are in greater need of mental health promotional services. Family planning should be made freely available in order to reduce the family size and hence incidence of mental illness in the African population. 
hold can create enormous pressure on individuals which may in turn affect their mental health $[5,6]$.

Available studies have been largely facility-based, while community- based studies have been very scanty. Several studies have been done using general health questionnaire (GHQ12) as a tool for screening mental illness in developed countries where the prevalence of psychiatric morbidity ranges between $17 \%-25 \%$ [6-8]. This study assessed the prevalence of and factors associated with mental illness in Oyo State at community level using the general health questionnaire as a screening tool. The public health significance of this study is that it will provide a conceptual framework for addressing mental health promotion goals. It also offers a highly appropriate framework through which community-based mental health activities could be addressed. Moreover, it could also be used for health planning and practice.

\section{Materials and methods}

The study was carried out in Oyo State one of the 36 states in Nigeria. This community based study is cross sectional in design and aimed at collecting data on mental health in rural and urban Oyo State, Nigeria.

\section{Sampling procedure}

Multistage sampling technique was used to obtain a representative sample of the communities in Oyo state. The communities where the study was carried out were chosen as follows:

\section{Stage 1}

A sampling frame of all the local government areas in Oyo state was drawn and stratified into urban and rural areas based on World bank classification [9]. One rural and two urban local government areas was obtained by simple random sampling (balloting). This is based on the fact that two thirds of Oyo state is urbanized. Ibadan NorthWest, Egbeda and Saki-East local government areas were selected.

\section{Stage 2}

Sampling frame of all the communities in the selected local government areas was drawn. The communities where the study was carried out were randomly selected by simple random sample (balloting). The communities selected were Idikan in Ibadan North-west LGA, Olubadan Estate in Egbeda LGA and Ago-amodu in Saki-East LGA.

\section{Stage 3}

Using the PHC house numbering where available (in places where it has not been done the houses were numbered for the purpose of the study). Systematic sampling technique was employed to select the houses that were visited in the chosen communities. Seventy-four houses were selected in Idikan, eighty-five houses in Olubadan Estate and ninety-eight houses in Ago-amodu.

\section{Stage 4}

One household in each of the houses selected were recruited into the study.

\section{Stage 5}

Every resident aged 15 years and above who has resided in the area for at least 6 months was interviewed in the households selected. A total of one thousand, one hundred and five subjects were recruited into the study.

A sample size formulae for comparing two proportions was used to obtain the sample size. Prevalence of $12.0 \%$ of poor mental health using GHQ 12 questionnaire among clinical students of University of Ibadan was used as estimate for urban community, while the prevalence of $21.3 \%$ among rural primary health care patients in Nigeria was used for rural community $[4,5]$. A precision of $95 \%$ is desired with a power of $90 \%$. The calculated sample size was 610 while this was doubled to 1220 with response rate of $90.6 \%$ (1105 responses).

\section{Data collection}

The study was conducted using an interviewer administered structured questionnaire. The GHQ-12 was used to assess mental health status of the respondents. Scores were calculated with a 0-1-1 scale with a maximum score of 1 and a minimum score of 0 for each item. A score of three or more was used as cut-off to classify into good and poor mental health. WHO quality of life questionnaire is a five point scale with items which ranged in rating from "very poor", "not at all" or "very dissatisfied" (1 point) to "very good", "extreme amount" or "very satisfied" (5 points). For items with reverse scores "not at all" was scored 5 and "extreme amount" was scored 1 . The score for both mentally healthy and mentally ill was computed to asses the effect of psychiatric morbidity on quality of life.

This questionnaire was translated into the local language for easy administration and translated back to English to ensure accuracy of translation. The GHQ (12) and WHO quality of life questionnaires were administered by research assistants after adequate training and the author's supervision. Research assistants were recruited from the communities and were trained to administer the questionnaires. The research assistants were recruited based on minimum qualification of OND certificate. They were trained on how to extract the information on psychiatric symptoms and their relevance to the research work. They were also guided through a good number of question- 
Table I: Socio-demographic characteristics and Mental Health Status

\begin{tabular}{|c|c|c|}
\hline Characteristics & Total No \& (\%) & Psychiatric Morbidity No \& (\%) \\
\hline \multicolumn{3}{|l|}{ Age } \\
\hline $15-19$ & $197(17.8)$ & $86(43.7)$ \\
\hline $20-39$ & $529(47.3)$ & $92(17.4)$ \\
\hline $40-64$ & $304(28.0)$ & $51(16.8)$ \\
\hline \multirow[t]{2}{*}{$>65$} & $75(6.9)$ & $13(17.3)$ \\
\hline & $1105(100.0)$ & $242(21.9)$ \\
\hline \multicolumn{3}{|l|}{ Sex } \\
\hline Male & $415(37.6)$ & $75(18.1)$ \\
\hline Female & $690(62.4) I 105(100.0)$ & $167(24.2) 242(21.9)$ \\
\hline \multicolumn{3}{|l|}{ Tribe } \\
\hline Indigenes & $1045(94.6)$ & $222(2 \mid .2)$ \\
\hline \multirow[t]{2}{*}{ Non- Indigenes } & $60(5.4)$ & $20(33.3)$ \\
\hline & $1105(100.0)$ & $242(21.9)$ \\
\hline \multicolumn{3}{|l|}{ Location } \\
\hline Urban & $721(65.3)$ & $133(18.4)$ \\
\hline \multirow[t]{2}{*}{ Rural } & $384(34.7)$ & $109(28.4)$ \\
\hline & $1105(100.0)$ & $242(21.9)$ \\
\hline
\end{tabular}

naires until a reasonable level of competence had been attained before being left to do it themselves.

Data generated in the study were manually cleaned and then entered into the Computer using SPSS 10 statistical software for analysis. Logistic regression analysis was done to determine factors associated with mental ill health in rural and urban Oyo State and also to remove the effect of confounding variables. The dependent variable was psychiatric morbidity as a dichotomous variable with a score of less than 3 being an option indicating good mental health while a score of 3 and more being another option indicating abnormal or psychiatric morbidity. All the variables which were significant in the bivariable anal-

Table 2: Family characteristics and Mental Health Status

\begin{tabular}{|c|c|c|}
\hline Characteristics & Total No \& (\%) & Psychiatric Morbidity No \& (\%) \\
\hline \multicolumn{3}{|l|}{ Marital Status } \\
\hline Single (Never Married) & $447(40.4)$ & $125(28.0)$ \\
\hline Married & $564(51.0)$ & $89(15.7)$ \\
\hline \multirow[t]{2}{*}{ Separated, Divorced or Widowed } & $94(8.6)$ & $28(29.8)$ \\
\hline & $1105(100.0)$ & $242(21.9)$ \\
\hline \multicolumn{3}{|l|}{ Type of family } \\
\hline Nuclear & $554(50.1)$ & $108(19.5)$ \\
\hline \multirow[t]{2}{*}{ Extended } & $551(49.9)$ & $114(20.7)$ \\
\hline & $1105(100.0)$ & $242(21.9)$ \\
\hline \multicolumn{3}{|l|}{ Type of Marriage } \\
\hline Monogamy & $542(49.0)$ & $112(20.7)$ \\
\hline \multirow[t]{2}{*}{ Polygamy } & $563(51.0$ & $130(23.1)$ \\
\hline & $1105(100.0)$ & $242(21.9)$ \\
\hline \multicolumn{3}{|l|}{ Family size } \\
\hline$<6$ & $793(71.8)$ & $126(15.9)$ \\
\hline \multirow[t]{2}{*}{$>6$} & $312(28.2)$ & $116(37.2)$ \\
\hline & $1105(100.0)$ & $242(21.9)$ \\
\hline
\end{tabular}


Table 3: Socio-economic characteristics and Mental Health Status

\begin{tabular}{|c|c|c|}
\hline Characteristics & Total No \& (\%) & Psychiatric Morbidity No \& (\%) \\
\hline \multicolumn{3}{|l|}{ Occupation } \\
\hline Senior Professional & $95(8.6)$ & $22(23.2)$ \\
\hline Junior Professional & $103(9.3)$ & $22(21.4)$ \\
\hline Skilled & $353(31.9)$ & $64(18.1)$ \\
\hline Unskilled & $400(36.2)$ & $67(16.8)$ \\
\hline Students & $75(6.2)$ & $28(37.3)$ \\
\hline \multirow[t]{2}{*}{ Unemployed } & $79(7.1)$ & $39(49.4)$ \\
\hline & $1105(100.0)$ & $242(21.9)$ \\
\hline \multicolumn{3}{|l|}{ Job Status } \\
\hline Employed & 924 (92.9) & $203(21.9)$ \\
\hline \multirow[t]{2}{*}{ Unemployed } & $79(7.1)$ & $39(49.4)$ \\
\hline & $1105(100.0)$ & $242(21.9)$ \\
\hline \multicolumn{3}{|l|}{ Education } \\
\hline Low & $475(43.0)$ & $90(18.9)$ \\
\hline \multirow[t]{2}{*}{ High } & $530(57.0$ & $152(24.1)$ \\
\hline & $1105(100.0)$ & $242(21.9)$ \\
\hline \multicolumn{3}{|l|}{ Physical health } \\
\hline Poor & $538(48.7)$ & $155(28.8)$ \\
\hline \multirow[t]{2}{*}{ Good } & $567(5 \mid .3)$ & $87(15.3)$ \\
\hline & $1105(100.0)$ & $242(21.9)$ \\
\hline \multicolumn{3}{|l|}{ Social health } \\
\hline Poor & $599(54.2$ & $183(30.5)$ \\
\hline \multirow[t]{2}{*}{ Good } & $506(45.8)$ & $59(11.7)$ \\
\hline & $1105(100.0)$ & $242(21.9)$ \\
\hline \multicolumn{3}{|l|}{ Living condition } \\
\hline Below average & $570(51.6)$ & $195(34.2)$ \\
\hline \multirow[t]{2}{*}{ Above average } & $535(48.4)$ & $47(8.8)$ \\
\hline & $1105(100.0)$ & $242(21.9)$ \\
\hline
\end{tabular}

ysis with a $\mathrm{p}<0.08$ were fed into the model. Odd ratios were adjusted and $\mathrm{p}$ values of $<0.05$ were taken as significant for the study.

\section{Results}

\section{Demographic characteristics}

Psychiatric morbidity was more prevalent in the rural population (28.4\%) compared with the urban population $(18.4 \%)\left(\mathrm{X}^{2}=3.69 \mathrm{p}=0.005\right)$. The adolescents in this study (15-19 yrs) had the highest prevalence of psychiatric morbidity $(43.7 \%, \mathrm{p}=0.00013)$ in Oyo state. The indigenes, that is, the Yorubas were more mentally stable when compared with the migrant tribes (the Ibos, Hausas and other minority tribes) $(21.2 \%$ vs $33.3 \% \mathrm{p}=0.253)$. Females had higher prevalence of psychiatric morbidity $\left(24.2 \%\right.$ vs $\left.18.1 \%, \mathrm{X}^{2}=0.83 \mathrm{p}=0.36\right)$.

\section{Family characteristics}

The Single (never married \& separated and divorced) had a higher morbidity rate when compared with the married $(p=0.091)$. This is shown in table 2. Fewer respondents living within the extended family structure had higher prevalence of mental ill-health when compared with those living within nuclear family structure, $\left(\mathrm{X}^{2}=0.09\right.$, $1 \mathrm{df} p=0.766)$. Those living within monogamous family structure had higher prevalence for psychiatry morbidity. $\left(\mathrm{X}^{2}=0.23, \mathrm{p}=0.634\right)$. Small sized families were significantly mentally healthier than large size families $\left(\mathrm{X}^{2}=\right.$ $14.09 \mathrm{p}=0.00017$ ).

\section{Socio- economic characteristics}

The unemployed had the highest prevalence for psychiatric morbidity when compared with the employed $\left(\mathrm{X}^{2}=\right.$ $11.86 \mathrm{p}=0.00058)$. Among those employed, the senior professionals had the highest unadjusted psychiatric morbidity rate $(23.2 \%)$ while the students had a relatively high prevalence of mental ill-health (37.3\%) when compared with others that are employed. Educational level was collapsed into two groups (high and low). Respondents with high level of formal education (secondary level 
Table 4: Adjusted Odds Ratio for the Risk of Mental Illness in Oyo State

\begin{tabular}{|c|c|c|c|}
\hline Variables & Odd Ratio & Confidence Interval & P-value \\
\hline Marital status & 1.34 & $0.84-2.10$ & 0.22 \\
\hline Not Married & 1.00 & & \\
\hline \multicolumn{4}{|l|}{ Married } \\
\hline Family size & 0.91 & $0.86-0.97$ & $<0.0005$ \\
\hline$<6$ & 1.00 & & \\
\hline \multicolumn{4}{|l|}{$>6$} \\
\hline Age & 0.72 & $0.18-2.90$ & 0.66 \\
\hline $15-19$ & 1.58 & $0.80-3.10$ & 0.19 \\
\hline $20-39$ & 1.24 & $0.78-1.90$ & 0.36 \\
\hline $40-64$ & 1.00 & & \\
\hline \multicolumn{4}{|l|}{$>64$} \\
\hline Location & 0.53 & $0.22-1.28$ & 0.158 \\
\hline Urban & 1.00 & & \\
\hline \multicolumn{4}{|l|}{ Rural } \\
\hline \multicolumn{4}{|l|}{ Living Condition } \\
\hline Below average & 3.30 & $1.99-5.50$ & 0.001 \\
\hline Above average & 1.00 & & \\
\hline \multicolumn{4}{|c|}{ Socio-economic class } \\
\hline unemployed & 2.10 & $1.18-3.70$ & 0.01 \\
\hline Low & 1.40 & $0.91-2.15$ & 0.12 \\
\hline High & 1.00 & & \\
\hline Social Health & 1.32 & $0.77-2.27$ & 0.31 \\
\hline Below average & 1.00 & & \\
\hline \multicolumn{4}{|l|}{ Above average } \\
\hline Physical Health & 1.58 & $0.99-2.52$ & 0.06 \\
\hline Below average & 1.00 & & \\
\hline Above average & & & \\
\hline
\end{tabular}

and above) had a higher morbidity rate than those with low level of formal education (Nil and primary) $\left(\mathrm{X}^{2}=\right.$ 0.97, $\mathrm{p}=0.325$ ).

The respondents who perceived their living condition to be above the average for their status were more mentally stable compared with those who did not $\left(\mathrm{X}^{2}=8.13 \mathrm{p}=\right.$ $0.0043)$. Those with chronic mental illness had a higher prevalence of psychiatric morbidity $\left(\mathrm{X}^{2}=6.07 \mathrm{p}=0.014\right)$. Furthermore, those with good social relationship were more mentally stable $\left(\mathrm{X}^{2}=8.13 \mathrm{p}=0.0043\right)$.

\section{Multivariate logistic analysis}

Table 4 shows the adjusted odds ratio and the confidence interval for the risk of mental illness in Oyo State. Family size greater than $6(p=0.002)$, reported living conditions above average $(\mathrm{p}=0.0001)$ and unemployment $(\mathrm{p}=$ 0.011 ) increased the risk of mental ill health. The presence of physical illness $(\mathrm{p}=0.056)$ was of borderline significance for mental illness.

\section{Discussion}

This study examined the prevalence of psychiatric morbidity in the urban and rural areas of Oyo state with a view to identify the factors that are associated with mental illness in the general population at the community level. The overall prevalence of psychiatric morbidity found at the community level in this study was $21.9 \%$. It is however slightly higher than what is found in other community-based surveys carried out in developed countries such as Spain, Canada, Norway and Australia [9-11].

The prevalence of psychiatric morbidity in the rural area was found to be significantly higher than the prevalence in the urban location. This is contrary to what was found in similar studies carried out in developed countries such as Great Britain where mental disorder was commoner in the urban areas than in the rural population [12]. The adolescent age group was found to have higher psychiatric morbidity when compared to the adults. Similar observations have been made in several studies $[21,22]$. The ado- 
lescent period is a turbulent period in life when there is transition into adulthood and self autonomy. This may explain the higher morbidity rates [23].

The study underlines the effect of family structure on the mental health of the population. Marriage was found to be associated with mental stability in Oyo state. Those separated from their spouses, divorcees and widows had a higher mental morbidity. Sticking to acceptable family structures may create mental tension in the communities studied. Aspiration to meet up to the community standards is usually a common source of mental stress. $[14,15]$. The indigenes were found to be more mentally stable than non-indigenes showing that migrants in Nigeria may be predisposed to setbacks psychologically when compared with the indigenes. This needs however to be further investigated as this is contrary to research done among Canadian Chinese migrants which shows that they do not suffer mentally compared with the general Chinese population [15].

Large family size and Unemployment was found to be associated with increase in psychiatric morbidity. This study corroborates the findings of several authors who found out that the larger the size of the family the lower the quality of child upbringing. This may lead to delinquent behavior among the children and increased mental stress on the care providers $[16,17]$. Unemployment is an important risk factor for mental illness and a significant determinant in the development of mental pathology especially among the adolescents [18]. However among those with employment the professionals had the highest morbidity rate. The possible reason for this in a Nigerian population is not immediately clear. Those with high level of formal education had higher psychiatric morbidity rate in the Nigerian community. This is similar to the conclusion of many authors $[19,20]$.

This study shows that prevalence of psychiatric morbidity is high in Oyo state, Nigeria and slightly higher than what is obtained in the community- based studies in the developed countries. The rural population is in greater need of mental health promotional services. Basic essential needs provided by the government in both rural and urban areas especially made available to the younger generation and promotion of family planning to reduce family size would help to reduce psychiatric morbidity and improve quality of life in this African population.

\section{References}

I. World Health Organization: Mental Health Division. Technical report 1993:I.

2. World Health Organization: Mental health division. Publication on World health day. Mental health around the World 200I:3.

3. World Health Organization: Quality of life assessment. World Health Chronicle 1976, 30(8):312.
4. Ohaeri JU, Odejide OA, Gureje O, Olatawura MO: The prevalence of psychiatric morbidity among adult attenders in the five PHC facilities of a rural community in Nigeria psychopathology africaine. 1994, 26(I):97-108.

5. Omokhodion FO, Gureje O: Psychological problems of clinical students in the University of Ibadan Medical School. Afr J Med Sci 2003, 32:55-58.

6. Odejide AO, Oyewunmi LK, Ohaeri JU: Psychiatry in Africa; An overview. Am J Psychiatric 1989, I46(6):708-716.

7. Goldberg D, Huskey P: common mental disorders. A Bio social model Routledge/tavistock publ London 1992.

8. Satoriuos N, Ushin Costa TB, Silva E, Goldberg D, Lecrubier $Y$, Ormel H, VonKorff M, Uwittchen : An International study of psychological problems in Primary care preliminary report from the WHO collaborative project on psychological problems in General health care Arch Gen Psychiat. 1993, 50:819-824.

9. World Bank Study: Classification of Oyo State into rural and urban settlement. 1998.

10. Rajimil L, Gispert MR, Roset GM, Munoz RE, Segura BA: Prevalence of mental disorders in the general population of Catalonia. Team of the Health Survey of Catalonia. Gaceta Sanitaria 1998, 12(4): 153-9.

II. Henderson S, Andrew G, Hall W: Australia's mental health: an overview of the general population survey. Volume 34 . Issue 2 Australian \& New Zealand Journal of Psychiatry.; 2000: 197-205.

12. Sandanger I, Nygard JF, Ingebrigsten G, Sorensen T, Dalgard O: Prevalence, incidence and age at onset of psychiatric disorders in Norway. Social Psychiatry \& Psychiatric Epidemiology 1999, 34(I I):570-9.

13. Paykel ES, Abbot R, Jenkins R, Brugha TS, Melzer H: Urban-rural mental health differences in Great Britain; findings from Nationals morbidity survey. Psychological Medicine 2000, 30(2):269-80.

14. Makanjuola ROA: Recurrent unipolar manic disorder in the Yoruba Nigeria, further evidence. Br J Psychiat 1985:434-437.

15. Gureje O, Obikoya BO, Ikueesan BA: Prevalence of specific disorders in an urban primary health care. E Afr Med J 1992, 69:282-287.

16. Lai DW: Measuring depression in Canada's elderly Chinese population: use of a community screening instrument. Canadian Journal of Psychiatry - Revue Canadienne de Psychiatrie 2000, 45(3):279-84.

17. Ebirahim GJ: Street children: a pediatric concern of growing proportions. J Trop Ped 1984, 30:I30-I.

18. UNICEF: The State of the World's children 1997 Oxford University Press, New York; 1997.

19. Mean Patterson LJ: Long-term unemployment amongst adolescents: A longitudinal study. Journal of Adolescence 1997, 20(3):26I-80.

20. Roberts R, Golding J, Towell T, Weinreb I: The effect of economic circumstances on British students' mental and physical health. J American college health 1999, 48(3): 103-9.

21. Eaton WW, Anthony JC, Madel W, Garrison R: Occupations and the prevalence of major depressive disorders. J Occup Med 1990, 32(II):.

22. Cosgrave $E$, McGorry $P$, Allen N, Jackson $H$ : Depression in young people. A growing challenge for primary care. Australian Family Physician 2000, 29(2): I23-7.

23. McKelvey R, Davies J, Pfaff J, Acres J, Edwards S: Psychological distress and suicidal ideation among 15 - 24-year-olds presenting to general practice: a pilot study. Australian \& New Zealand Journal of Psychiatry 1998, 32(3):344-8.

24. Solomon DA, Keitner GI, Miller IW, Shea MT, Keller M: Course of illness and maintainance treatments for patients with bipolar disorder. J Clin Psychiatry 1995, 56:5. 